\title{
Mechanism for the Formation of Cuprous Oxide Nanowires in AAO template by Electrodeposition
}

\author{
Babar Shazad Khan ${ }^{2}$, Adnan Saeed ${ }^{2}$, Sardar Sikandar Hayat ${ }^{3}$, Aiman Mukhtar $^{1}$, Tahir Mehmood, ${ }^{1, *}$ \\ ${ }^{1}$ The state key laboratory of Refractories and Metallurgy, Hubei Collaborative Innovation Center for \\ Advanced Steels, International Research Institute for Steel Technology, Wuhan University of Science \\ and Technology, Wuhan, P. R. China \\ ${ }^{2}$ Department of Physics, Government College Women University, 51310, Sialkot, Pakistan \\ ${ }^{3}$ Department of Physics, Hazara University, 21300, Mansehra, Pakistan \\ *E-mail: tahir10621@yahoo.com
}

doi: $10.20964 / 2017.02 .42$

Received: 25 September 2016 / Accepted: 16 December 2016 / Published: 30 December 2016

The effect of potential and $\mathrm{pH}$ on the formation of $\mathrm{Cu} 2 \mathrm{O}$ and $\mathrm{Cu}$ nanowires in AAO template have systematically been studied by Potentiostate, XRD, SEM, TEM and EDX. The pure Cu2O nanowires were electrodeposited at voltage $(-0.3 \mathrm{~V})$ and $\mathrm{pH}(8.2)$. At higher voltage $(-0.6 \mathrm{~V}$ and $-0.5 \mathrm{~V})$ with low $\mathrm{pH} 8.2$, there was co-existence of $\mathrm{Cu}$ and $\mathrm{Cu} 2 \mathrm{O}$ nanowires. At voltage $-0.5 \mathrm{~V}$ with $\mathrm{pH} 9$, the pure $\mathrm{Cu} 2 \mathrm{O}$ nanowires are formed. A mechanism is proposed for the formation of cuprous oxides nanowires. The formation of pure $\mathrm{Cu} 2 \mathrm{O}$ nanowires can be attributed to the formation of large size critical $\mathrm{Cu}$ nuclei, the larger size of nuclei favors the formation of pure cuprous oxides nanowires.

Keywords: Electrochemical Deposition; Cuprous Oxide; Growth; Nanowires

\section{FULL TEXT}

(C) 2017 The Authors. Published by ESG (www.electrochemsci.org). This article is an open access article distributed under the terms and conditions of the Creative Commons Attribution license (http://creativecommons.org/licenses/by/4.0/). 